\title{
RESPON PERTUMBUHAN DAN PRODUKSI BAWANG MERAH (ALLIUM ASCALONICUM) TERHADAP PEMBERIAN JENIS MULSA DAN PUPUK KANDANG AYAM DI DESA WATUMILOK KECAMATAN KANGAE KABUPATEN SIKKA
}

\author{
Yovita Yasintha Bolly \\ Program Studi Agroteknologi, Fakultas Pertanian Universitas Nusa Nipa \\ Vytayovieeta@gmail.com
}

\begin{abstract}
The aim of the study was to find out how the response of onion plants to the administration of mulch and chicken manure was designed using factorial Randomized Block Design (RBD) consisting of 2 factors with 5 treatments and 3 replications. Factor I: The use of Mulch (M) with 3 types, consisting of M0 (without mulch), M1 (rice straw mulch), M2 (Black silver plastic mulch) and Factor II: Chicken manure (P) with 5 levels consisting of P0 ( Without fertilizer), P1 (10 tons / ha or $1 \mathrm{~kg} /$ bed), P2 (20 tons / ha or $2 \mathrm{~kg} / \mathrm{bed}), \mathrm{P} 3$ (30 tons / ha or 3 $\mathrm{kg} / \mathrm{bed}$ ) and P4 (40 tons / ha or $4 \mathrm{~kg} / \mathrm{bed}$ ). Observations of age 2 and 6 MST showed that the best treatment was rice straw mulch (M1) where the combination treatment was M1P4 with an average of $34.99 \mathrm{~cm}$ in the treatment without mulch (M0) and rice straw mulch (M1). For the number of leaves aged 2 MST showed that the best treatment was rice straw mulch (M1) in the M1P4 combination with a mean of 15.59 strands. Whereas in the second observation the number of leaves aged 6 MST from each treatment was the highest in rice straw mulch (M1) in the M1P4 treatment combined with an average of 46.78 strands. The observation of wet weight on shallots aged 65 HST showed that the combination of mulch and chicken manure on shallots had the first average wet weight in the treatment combination (MOP2) with an average value of $181.48 \mathrm{gr}$.
\end{abstract}

Keywords: Shallots, Mulch, Fertilizer Cages

\section{PENDAHULUAN}

Bawang merah (allium ascalonicum) merupakan komoditi yang memiliki prospek dalam usaha pertanian. Permintaan akan bawang merah selalu meningkat dari waktu ke waktu, (Sugiharto, 2006; Kanisius, 1998).Untuk mendapatkan produksi bawang merah yang optimal maka yang perlu diperhatikan dalam sistem budidaya adalah faktor tanah.Tanah yang baik untuk pertumbuhan bawang merah adalah tanah yang lembab solusinya dengan pemulsaan.Keuntungan penggunaan mulsa adalah dapat meningkatkan dan memperbaiki kualitas hasil umbi tanaman, dan memungkinkan penanaman di luar musim serta perbaikan teknik budidaya (Barus, 2006).Penelitian Tabrani et al. (2005) menunjukkan penggunaan mulsa alang-alang, plastik transparan dan mulsa plastic hitam perak berpengaruh terhadap semua parameter bawang merah yang diamati.Penelitian Ansar (2012) menjelaskanbahwa pemberian mulsa jerami padi dan mulsa plastik hitam dapat meningkatkan bobot segar umbi per hektar masing-masing $29,3 \%$ dan $24 \%$ dibanding tanpa mulsa. 
Desa watumilok, Kecamatan Kangae merupakan salah satu daerah sentral pertanian dengan aktivitas tinggi..sehingga tidak dipungkiri bahwa jumlah hara dalam tanah dan air menjadi salah satu faktor pembatas produksi. Maka usahamengatasi ketersediaan unsur hara dalam tanah adalah melalui pemupukan (Lingga dkk, 2009).

Upaya untuk meningkatkan produksi bawang merah lokal melalui teknik budidaya adalah dengan pemberian pupuk kandang (Latarang dan Syukur, 2006). Pupuk kadang ayam broiler mempunyai kadar hara $\mathrm{P}$ yang relatif tinggi dari yang lainya (Hartatik dan Widowati, 2010). Hasil penelitian Rahmah (2013) dapat disimpulkan bahwa pemberian pupuk kandang ayam nyata meningkatkan tinggi tanaman, jumlah anakan per rumpun, jumlah daun, bobot basah umbi per sampel, bobot kering umbi per sampel, bobot basah umbi per plot, bobot kering umbi per plot dan jumlah siung per sampel. Secara umum pemberian pupuk kandang ayam 120 g/tanaman meningkatkan pertumbuhan dan produksi bawang merah.

Untuk itu peneliti melakukan penelitian tentang "Respon Pertumbuhan Dan Produksi Bawang Merah (allium ascalonicum) Terhadap Pemberian Jenis Mulsa Dan Pupuk Kandang Ayam Di Desa Watumilok Kecamatan Kangae Kabupaten Sikka".

\section{METODE PENELITIAN}

\section{Tempat dan Waktu Penelitian}

Penelitian ini sudah dilaksanakan pada bulan Mei sampai September 2017 di Desa Watumilok Kecamatan Kangae Kabupaten Sikka.

\begin{abstract}
Alat dan Bahan
Alat-alat yang diperlukan dalam penelitian ini adalah: skop, pacul, ember, meter,gembor, tali, parang, sabit, alat tulis menulis, mistar, dan kamera. Sedangkan bahan yang diperlukan dalam penelitian ini adalah: tanah, pupuk kandang ayam, mulsa jerami padi, mulsa plastik hitam perak, air, dan bawang merah varietas Bima dengan ukuran $1,8 \mathrm{~cm}$ atau 10 gr. Umbi benih yang baik untuk ditanam tidak mengandung penyakit, tidak cacat, dan tidak terlalu lama disimpan di gudang.
\end{abstract}

\section{Rancangan Penelitian}

Rancangan yang digunakan dalam penelitian ini adalah Rancangan Acak Kelompok (RAK) faktorial yang terdiri dari 2 faktor dengan 5 perlakuan dan 3 kali ulangan. Faktor I : Penggunaan Mulsa (M) dengan 3 jenis, terdiri atas $\mathrm{M}_{0}$ : Tanpa mulsa, $\mathbf{M}_{1}$ : Mulsa jerami padi, $\mathbf{M}_{2}$ : Mulsa Plastik hitam perak, Faktor II : Pupuk kandang ayam $(\mathrm{P})$ dengan 5 taraf terdiri atas : $\mathrm{P}_{0}$ : Tanpa pupuk

$\mathrm{P}_{1}: 10$ ton/ha atau $1 \mathrm{~kg} /$ bedeng, $\mathrm{P}_{2}: 20$ ton/ha atau $2 \mathrm{~kg} /$ bedeng, $\mathrm{P}_{3}: 30$ ton/ha atau $3 \mathrm{~kg} /$ bedeng, $\quad \mathrm{P}_{4}: 40$ ton/ha atau 4 $\mathrm{kg} / \mathrm{bedeng}$

\section{Prosedur Kerja}

Tahapan yang dilakukan dalam penelitian ini adalah Pemilihan Bawang Merah, Persiapan lahan, Pengolahan tanah, Pembuatan bedengan, Penebaran pupuk kandang ayam, Pemasangan Mulsa, Penanaman, Pengairan, Penyiangan, Pengendalian hama dan penyakit dan Panen.

\section{Variabel Pengamatan}

Variabel yang diamati dalam penelitian ini terdiri dari variabel utama yaitu tinggi tanaman $(\mathrm{cm})$, jumlah daun 


\section{Bolly : ResponBawang Merah Terhadap Mulsa dan Pupuk Kandang Ayam}

(helai) dan bobot basah perpohon (gr) dan variabelpenunjang terdiri dari analisis tanah awal kandungan $\mathrm{N}, \mathrm{P}, \mathrm{K}$ C-organik, $\mathrm{pH}$ tanah sebelum melakukan penelitian.

\section{Model Analisis Data}

Model analisis data Rancangan Acak Kelompok (RAK) 2 faktorial menurut Herdiyantoro (2013) adalah sebagai berikut:

$$
\begin{aligned}
& Y_{i j k}=\mu+\alpha_{i}+\beta_{j}+(\alpha \beta)_{i j}+\rho_{k}+\sum_{i j k} \\
& i=1,2, \ldots . . ., r ;=1,2, \ldots . . ., a ; k= \\
& 1,2, \ldots, b
\end{aligned}
$$

Data yang diperoleh dianalisis dengan menggunakan rancangan acak kelompok (RAK) dan bila hasil uji ANOVA (Analisis of Variance)berbeda tidak nyata (F hitung < F tabel $5 \%$ ) tidak dilakukan uji lanjutan, sedangkan bila hasil sidik ragam berbeda nyata ( $\mathrm{F}$ hitung $>\mathrm{F}$ tabel $5 \%$ ) atau berbeda sangat nyata (F hitung $>\mathrm{F}$ tabel $1 \%$ ), maka untuk membandingkan dua rata-rata perlakuan dilakukan uji lanjutan dengan uji Beda Nyata Terkecil (BNT) taraf $5 \%$.

\section{HASIL DAN PEMBAHASAN}

\section{Hasil Analisis Tanah Awal}

Analisis tanah awal telah dilaksankan di Laboratorium Kimia Tanah Fakultas Pertanian Universitas Nusa Cendana Kupang. Tanah analisis diambil di lokasi penelitian

Berdasarkan hasil analisis laboratorium, kondisi tanah yang digunakan dalam penelitian ini memiliki kandungan bahan $\mathrm{C}$ - organik tergolong rendah yaitu $4,5 \%$ dan kandungan $\mathrm{N}$ total 0,33\% tergolong sedang, sedangkan kandungan $\mathrm{P}_{2} \mathrm{O}_{5}$ yaitu 28,93 ppm tergolong tinggi, serta kandungan $\mathrm{K}$ yaitu $1,17 \mathrm{me} / 100 \mathrm{~g}$ tergolong tinggi, serta kondisi $\mathrm{pH}$ tanah yaitu 6,90 dengan kategori netral.

\section{Pengamatan Tinggi Tanaman Tinggi Tanaman 2 dan 6 MST}

Hasil pengamatan tinggi tanaman bawang merah umur 2 MST menujukkan bahwa kombinasi pemberian jenis mulsa dan pupuk kandang ayam pada tanaman bawang merah memiliki rata-rata tertinggi pada mulsa jerami padi (M1) pada kombinasi perlakuan M1P4 dengan rerata $22,83 \mathrm{~cm}$ disusul mulsa plastik hitam perak (M2) pada kombinasi perlakuan M2P4 dengan nilai rerata $22,13 \mathrm{~cm}$, pada perlakuan tanpa mulsa (M0) pada kombinasi perlakuan M0P4 dengan nilai rerata $21,33 \mathrm{~cm}$ dan kombinasi perlakuan terendah pada M0P0 dengan rerata 15,89 $\mathrm{cm}$.

Sedangkan pada pengamatan kedua tinggi tanaman bawang merah umur $6 \mathrm{mst}$, angka tetinggi pada perlakuan mulsa jerami padi (M1) pada kombinasi perlakuan M1P4 dengan rerata $47,15 \mathrm{~cm}$ disusul mulsa plastik hitam perak (M2) pada kombinasi perlakuan M2P4 dengan rerata $45,10 \mathrm{~cm}$, pada perlakuan tanpa mulsa (M0) pada kombinasi perlakuan M0P4 dengan rerata $43,99 \mathrm{~cm}$. dan kombinasi perlakuan terendah pada M0P0 dengan rerata 23,96 $\mathrm{cm}$. Pengamatan tinggi tanaman umur 2 dan 6 MST, terlihat jelas bahwa perlakuan kombinasi pupuk kandang ayam dengan mulsa (jerami padi dan plastik hitam perak) memiliki nilai rerata tertinggi bila dibandingkan tanpa mulsa dan tanpa pupuk kandang ayam. Hal ini diduga karena mulsa jerami padi dan mulsa plastik hitam perak dapat menyimpan dan menahan air dari penguapan untuk keperluan tanaman (Ansar, 2012). Dengan adanya mulsa jerami padi dan mulsa plastik hitam perak maka tanah lebih terjaga dari suhu maupun curah hujan. 

Menurut Barus, (2006) pemulsaan merupakan suatu cara memperbaiki tata udara tanah dan juga tersedianya air bagi tanaman. Selain itu pemberian mulsa dapat mempercepat pertumbuhan tanaman yang baru ditanam. Hasil penelitian Tabrani $\mathrm{d} k k$ (2005) menerangkan bahwa perlakuan mulsa plastik hitam perak meningkatkan tinggi tanaman, bobot basah, dan bobot produksi bawang merah bila dibandingkan tanpa mulsa. Selain penggunaan mulsa salah satu upaya dalam memacu pertumbuhan bawang merah adalah pemberian pupuk kandang ayam.Menurut Yetti $d k k$, (2008) pemberian pupuk organik sangat baik digunakan untuk memperbaiki sifat fisik, kimia dan biologi tanah, meningkatkan aktivitas mikroorganisme tanah dan lebih ramah lingkungan. Menurut Hartatik danWidowati (2010), pupuk kandang ayam mengandung 57\% $\mathrm{H} 2 \mathrm{O}$, $29 \%$ bahan organik, $1,5 \% \mathrm{~N}, 1,3 \% \mathrm{P} 2 \mathrm{O} 5$, $0,8 \% \mathrm{~K} 2 \mathrm{O}, 4 \% \mathrm{CaO}$ dengan rasio $\mathrm{C} / \mathrm{N}$ 911 .

Menurut Samadi dan Cahyono, (2005) dosis pupuk kandang ayam yang terbaik untuk tanaman bawang merah adalah 20 ton per hektar.Dalam penelitian Rahmah, (2013) menjelaskan bahwa pemberian pupuk kandang ayam dapat meningkatkan tinggi tanaman, jumlah anakan per rumpun, jumlah daun, bobot basah umbi per sampel.bobot kering umbi per sampel, bobot basah umbi per plot, bobot kering umbi per plot dan jumlah siung per sampel. Secara umum pemberian pupuk kandang ayam 120 g/tanaman meningkatkan pertumbuhan dan produksi bawang merah.

\section{Pengamatan Jumlah Daun Jumlah daun 2 dan 6 MST}

Hasil pengamatan jumlah daun tanaman bawang merah umur 2
MST,menujukkan bahwa kombinasi pemberian jenis mulsa dan pupuk kandang ayam pada tanaman bawang merah memiliki rata-rata tertinggi pada mulsa jerami padi (M1) pada kombinasi perlakuan M1P4 dengan rerata 15,59 helai disusul mulsa plastik hitam perak (M2) pada kombinasi perlakuan M2P4 dengan nilai rerata 14,89 helai, pada perlakuan tanpa mulsa (M0) pada kombinasi perlakuan MOP4 dengan nilai rerata 14,74 helai, dan kombinasi perlakuan terendah pada M0P0 dengan rerata 10,93 helai.

Sedangkan pada jumlah daun umur 6 MST, angka tetinggi pada perlakuan mulsa jerami padi (M1) pada kombinasi perlakuan M1P4 dengan rerata 46,78 helai disusul mulsa plastik hitam perak (M2) pada kombinasi perlakuan M2P4 dengan rerata 44,30 helai, pada perlakuan tanpa mulsa (M0) pada kombinasi perlakuan M0P4 dengan rerata 43,11 helai dan kombinasi perlakuan terendah pada M0P0 dengan rerata 26,70 helai.

Dari hasil pengamatan jumlah daun pada tanaman bawang merah umur 2 dan 6 MST juga terlihat jelas bahwa kombinasi pupuk kandang ayam dan penggunaan jenis mulsa (jerami dan plastik perak) berbanding terbalik dengan tanpa pemberian mulsa dan tanpa pupuk kandang ayam.Penggunaan mulsa dan kombinasi pupuk kandang ayam dalam penelitian ini memiliki nilai rerata tertinggi bila dibandingkan tanpa mulsa dan tanpa pupuk kandang ayam. Menurut Umboh (2000), salah satu upaya memanipulasi lingkungan tanaman yaitu dengan pemberian mulsa. Melalui teknologi pemulsaan dapat menurunkan suhu tanah, mencegah evaporasi dan akibatnya lahan tidak kekurangan air, maupun menahan butiran air hujan, serta mencegah persaingan tanaman penganggu sehingga dapat meningkatkan produksi tanaman. 
Hasil penelitian Tabrani $d k k$, (2005) menunjukan penggunaan mulsa alangalang, plastik transparan dan mulsa plastik hitam perak berpengaruh terhadap semua parameter bawang merah yang diamati.Sementara hasil penelitian Mayun (2007), terjadi perbedaan yang nyata antara pemberian mulsa jerami padi (M1) dengan tanpa pemberian mulsa (MO) terhadap jumlah daun per rumpun pada hasil umbi. Pemberian mulsa jerami padi dapat meningkatkan hasil umbi kering sebesar 4,49 Ku Ha-1 atau terjadi peningkatan sebesar $35,13 \%$..

\section{Pengamatan bobot basah 65 HST}

Bobot basah pada tanaman bawang merah umur 65 HST, memiliki rata-rata berat bobot basah pertama pada kombinasi perlakuan (MOP2) dengan nilai rerata 181,48 gr. Dan rata-rata besar bobot basah kedua pada kombinasi perlakuan (MOP4) yaitu 162,96 gr, (M1P3) yaitu 162,96 gr, (M2P3) yaitu 162,96 gr . dan bobot basah terendah pada kombinasi perlakuan (MOPO) dengan nilai rerata 107,41 gr.

Dari data tersebut terlihat jelas bahwa tidak ada pengaruh yang signifikan antara penggunaan mulsa (jerami dan plastik perak) dan pupuk kandang ayam terhadap berat bobot basah umbi bawang merah umur 65 HST. Menurut Sutedjo (2002), pupuk kandang segar mempunyai $\mathrm{C} / \mathrm{N}=25$. Bila langsung dipupuk kedalam tanah jasad renik akan menarik $\mathrm{N}$ dari dalam tanah, kenyataanya dalam penarikan $\mathrm{N}$ ini akan berlangsung persaingan diantara jasad renik, peristiwa persaingan antara jasad renik didalam tanah disebut immobilisasi.

\section{SIMPULAN}

Berdasarkan data hasil penelitian dan pembahasan tersebut di atas dapat disimpulkan bahwa :
1.Tinggi tanaman umur 2 MST menunjukkan bahwa perlakuan terbaik adalah mulsa jerami padi (M1) dengan kombinasi perlakuan M1P4 dengan rerata $22,83 \mathrm{~cm}$. Sedangkan pengamatan kedua tinggi tanaman umur 6 MST memiliki rata-rata tertinggi pada perlakuan mulsa jerami padi (M1) pada kombinasi perlakuan M1P4 dengan rerata 47,15 cm.

2.pengamatan jumlah daun tanaman bawang merah umur 2 MSTmenujukkan bahwa perlakuan terbaik adalah mulsa jerami padi (M1) dengan kombinasi perlakuan M1P4 dengan rerata 15,59 helai. Sedangkan pada umur 6 MST, perlakuan terbaik adalahmulsa jerami padi (M1) pada kombinasi M1P4 dengan rerata 46,78 helai.

3.Bobot basah pada umur 65 HST menujukkan bahwa kombinasi terbaik adalah MOP2 dengan nilai rerata 181,48 gr.

\section{UCAPAN TERIMA KASIH}

Pada kesempatan ini penulis ingin mengucapkan terima kasih kepada semua pihak yang telah membantu dengan caranya masing-masing dalam melengkapi tulisan ini.

\section{DAFTAR PUSTAKA}

Ansar,M.2012.Pertumbuhan Dan Hasil Bawang Merah Pada Keragaman Ketinggian Tempat.Disertasi.Universitas Gajah Mada Yogyakarta.

Barus,W.A.2006. Pertumbuhan dan produksi cabai(capsicum annum L.)dengan penggunaan mulsa dan pemupukan PK. Penelitian bidang ilmu pertanian4(1):41-44.

Hartatik,W. Dan L.R.Widowati, 2010. Pupuk Kandang.

Hardjowigeno, S. 2003. Ilmu Tanah. AkademikaPressindo.Jakarta 
Herdiyantoro, 2013.Perancangan

Percobaan. https: //Herdiyantoro. files. wordpress. Com / diakses 19/03/2017

Kanisius, 1998. Pedoman Bertanam Bawang. Yokyakarta.

Latarang, B dan Abdul, S., 2006.Pertumbuhan dan Hasil Bawang Merah (Allium ascalonicumL.) Pada Berbagai Dosis Pupuk Kandang . J. Agroland 13 (3) : 265-269.

Lingga, Pinus dan Marsono, 2009.Petunjuk Pemakaian Pupuk. Jakarta, Penebar Swadaya.

Mayun, I. A. 2007. Efek Mulsa Jerami Padi dan Pupuk Kandang Sapi terhadap Pertumbuhan dan Hasil Bawang Merah di Daerah Pesisir.J. Agritrop $26(1): 33-40$.

Rahmah,A.2013. Pertumbuhan dan produksi bawang merah(allium ascalonicum L.)dengan pemberian pupuk kandang ayam dan Em4(effective microorganisme4).J.online agroteknologi 1(4):

Sutedjo, M. M. dan A. G. Kartasapoetra. 2002. Pengantar Ilmu Tanah. Bina Aksara, Jakarta.

Samadi, B dan B. Cahyono. 2005. Intensifikasi Usaha Tani Budidaya Bawang Merah. Kanisius, Yogyakarta.

Sugiharto, 2006. Budidaya Tanaman Bawang Merah. Semarang, CV Aneka Ilmu.

Suharyanto danJ. Rinaldi, 2010.Estimasi Potensi dan Nilai Ekonomis Pupuk Kandang di Bali. Balai Pengkajian Teknologi Pertanian (BPTP), Bali

Tabrani, G., R. Arisanti dan Gusmawartati. 2005. Peningkatan Produksi Bawang Merah (Allium ascalonicum L.) dengan Pemberian Pupuk $\mathrm{KCl}$ dan Mulsa. J. Sagu 4(1):24-31.

Umboh, H.A. 2000.Petunjuk Penggunaan Mulsa. PT. Penebar Swadaya.Jakarata.
Wibowo, singgih. 2006. Budidaya Bawang Merah,Varietas Bawang Merah. Penebar Swadaya. Jakarta.

Yetti, H dan E. Elita. 2008. Penggunaan Pupuk Organik dan $\mathrm{KCl}$ pada Tanaman Bawang Merah (Allium ascalonicum L.). J. Sagu 7(1):13-18. 